Running head: SUICIDAL IDEATION IN MEDICAL RECORDS

Construction of suicidal ideation in medical records

\author{
Dariusz Galasiński \\ University of Wolverhampton, Wolverhampton, $U K$
}

Justyna Ziółkowska

University of Social Sciences and Humanities, Wroclaw Faculty, PL

Correspondence concerning this article should be addressed to Dariusz Galasinski University of Wolverhampton, Faculty of Arts, Wulfruna Street, Wolverhampton, WV1 1LY, UK.

Tel: +44(0)1902 323489; Fax:+44(0)1902 322739 Email: d.galasinski@wlv.ac.uk

This research was supported by the National Science Centre in Poland under Grant SONATA 2012/05/D/HS6/02390. 


\begin{abstract}
In this paper we are interested in exploring discursive transformation of patients' stories of suicidal ideation into medical discourses. In other words, we focus on how the narrated experience of suicidal thoughts made during the psychiatric assessment interview is recorded in the patients' medical record. Our data come from recordings of psychiatric interviews, as well as the doctors' notes in the medical records made after the interviews collected in psychiatric hospitals in Poland. Assuming a constructionist view of discourse, we demonstrate that lived experience of suicide ideation resulting in stories of a complex and homogeneous group of 'thoughts' is reduced to brief statements of fact of presence/existence. Exploration of the relationship between the interviews and the notes suggest a stark imposition of the medical gaze upon them. We end with arguments that discursive practices relegating lived experience from the focus of clinical practice deprives it of information which is meaningful and clinically significant.
\end{abstract}

Keywords: suicidal ideation, medical records, discourse analysis, qualitative study 


\section{Construction of suicidal ideation in medical records}

In suicidology, studies on medical records are focused on identification of socio-medical factors associated with the risk of suicide. Usually, researchers treat medical records as a set of objective data about patients and they look for patterns in the records that indicate heightened risk of suicide in individual patients (Poulin et al., 2014; Laukkala, Partonen, Marttunen \& Henriksson, 2014; Mallon, Galway, Hughes, Rondón-Sulbarán \& Leavey, 2016). In our article we want to look at medical records from a different perspective. We are interested in how doctors construct suicidal experiences of patients in their medical records. We also assume that medical records are a source of information about institutional practices and the analyses of medical records about suicidal experiences of hospitalized patients allow us to better understand clinical care of suicidal patients.

\section{Medical records}

One of the basic clinical skills as well as requirements of the physician is to record their clinical encounters with the patient, detailing examination, observation and the care provided (Tasman \& Mohr, 2011; also Higgs \& Jones, 2000). The note should be clear, specific and provide the reader with information which is both specific and relevant for further care. Admittedly, the task is difficult as sometimes patients tell doctors much more that might be required clinically, and sometimes patients may not disclose suicide ideation voluntarily (e.g. Waldinger, 1997). Thus, a note in the patient's record enforces selection and management of the information collected during the encounter. This process is of particular importance in the case of suicide risk, where the clinical encounter is usually the only source of information available to the doctor. 
Clinical notes are written in two contexts. One is the medico-legal context (medical documentation is used in social security contexts, courts, or by local administration) requiring doctors to keep record of the patient's progress and treatment, the other is clinical practice often suggesting patterns of constructing records; in other words, clinicians write notes 'as one writes' them. Indeed, ways of constructing the record and represent clinical reality within it can say much about how doctors view the patient and his/her problems, revealing the priorities and assumptions in clinical practice. As More and Noone (1997) argue, "medical record sometimes can say more about the staff than about the condition of the patient" (More \& Noone, 1997: 325; see also: Buss, 2009; Heartfield, 1996; Perron \& Holmes, 2011). As clinical records are all that remains after the patient's examination, the records inform and legitimise clinical actions taken by medical staff. From a researcher's point of view, they can also offer insight into clinical practice.

In Poland, where our study was carried out, patients have a right to access their medical documentation, however, this right is deemed to be unobserved in the highest degree. In 2015, 35 per cent of all cases considered by the patient ombudsman concerned mishandling of patient documentation (The Commissioner for Patients' Rights, 2016). And so, in everyday practice, medical documentation only available to healthcare professionals on the ward, such as doctors and nurses and They can therefore be seen both as a means of keeping record of patients' progress as well as communicating between clinical staff.

\section{Suicidal risk in hospital and medical records}

Even though there is no evidence that inpatient hospitalization reduces rates of suicide (Galardy \& Lineberry, 2013; Huber, et al., 2016), psychiatric hospitalization is the standard of care for suicidal patients at risk of suicide. Assessment of suicide risk is one of the most important parts 
of a clinician's job and it is the first step in the care of a suicidal patient (e.g. Simon, 2008a; Chehil \& Kutcher, 2012), there is, however, no commonly accepted procedure of such assessment. The clinical interview, focused on gaining insight into the person's experiences is the crucial element, in assessing suicide risk. And so, doctors are advised to discuss for example current suicidal thoughts, suicidal intent and plans, history and lethality of previous attempts, the attitude toward the attempt, family history of suicide/suicide attempts as well as social or family support (see e.g. Simon \& Hales, 2012). There are also some supporting instruments; those which adopt a structured approach [CAMS - the Collaborative Assessment and Management of Suicidality (Jobes, 2006) and CASE - The Chronological Assessment of Suicide Events (Shea, 2009a, 2009b)], and a number of diagnostic questionnaires that are aimed to help clinicians in the assessment of suicidal risk [SSI - The Scale for Suicidal Ideation (Beck, Kovacs \& Weissman, 1979), SSF-II - The Suicide Status Form-II (Jobes, Jacoby, Cimbolic \& Hustead, 1997; Conrad, 2009), SIS - The Suicide Intent Scale (Beck, Schuyler \& Herman, 1974)].

Still, as Galardy and Lineberry (2013) argue, inadequate assessment of suicidal risk is responsible for $80 \%$ of inpatient suicides. Partly this is due to high dynamics of the suicide process (Fartacek, Schiepek, Kunrath, Fartacek, \& Plöderl, 2016), yet the Joint Commission (2016) which accredits medical services in the Unites States points to shortcomings in psychiatric assessment of patients receiving care, which occur even though there are guidelines and procedures for assessment of suicide risk. They call for better detection of suicide ideation as well as solid records in medical documentations.

As medical records become the main method of communication among providers of care suicidologists stress the role of documenting every step of the diagnostic and therapeutic processes and all communication with patient, his/her family and other clinicians (e.g. Kapur, 2002; The Joint Commission, 2016). It's also important in the context of legal consequences of 
poor record keeping (Simpson \& Stacy, 2004). Authors refer to the old adage: 'If it's not written down, it didn't happen". As clinicians' records provide evidence of their involvement in care of patients, thorough records are crucial to provide proof of their work (Griffith, 2007). In fact, suicide is the most common cause of legal action against mental health care professionals (Simpson \& Stacy, 2004).

Considering the role of medical documentation, it is surprising that we could not find studies on suicidal ideation in medical documentation. There are many texts about the role of medical documentation as well as many guidelines in writing such records (e.g. Carrigan \& Lynch, 2003), yet, actual records on suicidal experiences and behaviours haven't been studied.

\section{Aims and assumptions}

The aim of this article is to explore constructions of suicidal ideation in medical documentation. In particular, we are interested in exploration of the sources of those constructions, examining the relationship between patients' accounts of suicidal ideation during the clinical/diagnostic interview and the medical records. We shall argue that suicide ideation is not constructed as experience, but only as an institutional problem.

We are interested in suicidal thoughts, because assessment of suicidal thoughts/ideation is a key element of suicide risk assessment. Scholars who study the process leading to suicide take the initial wish to die or thoughts about death as the beginning of the suicidal process (Neeleman, de Graaf, \& Vollebergh, 2004; Runeson, Beskow, \& Waern, 1996; Deisenhammer, Strauss, Kemmler, Hinterhuber, \& Weiss, 2009). And so, suicidal thoughts are considered as a key indicator of suicide risk. Especially that suicidal ideation is also linked with suicidal intent and indicates the extent to which an "ideator" wants to die (e.g. Beck et al., 1979). 
In this article we report on qualitative research. We look at the lifeworld taking the perspective of the people who participate in the research. Adopting a constructionist view, we assume that social reality is a continual product of social exchanges of meanings, which offer a way in which social participants can access objective reality. Moreover, by taking the 'inside' perspective, qualitative research is more 'engaged'. As we live in a social world which becomes increasingly unfixed, it is particularly the in-depth description thereof, and from the point of view of the social actor, that becomes significant. It is also through adopting the bottom-up perspective that we are able to engage with increasingly frequent calls to involve research participants, particularly those perceived as disenfranchised, in the research design, its process and dissemination of results (e.g. Davidson, 2003).

We present results of a discourse analysis. We focus on language, on ways in which it is used and not as a system of vocabulary and grammar. We focus upon the content and the form of stretches of discourse with an interest in the functions of what is said within the local context, and the social actions thus accomplished. We understand discourse as a form of social practice within the socio-cultural context. This means that language users, as members of multiple social groups, speak the way one speaks, the way it is appropriate (in many senses of this word) to speak.

More specifically, we anchor our study within the critically oriented analysis of discourse (e.g. Fairclough, 1992; Hodge \& Kress, 1993; van Dijk, 1993; Barker \& Galasinski, 2001). Thus, we assume that discursive representations, whether linguistic (spoken or written) or visual are not transparent, but, rather, construct reality as much as they represent it. At lexical as well as syntactic-semantic and pragmatic levels language use is associated with a 'structure of faith' (Menz, 1989): patterns of belief and values and of their textual representations (often multiple and contradictory). And so, we are interested in discourse as a means of systematic social construction of knowledges, subjects and worlds of which it speaks (Foucault, 1973). Discourse 
analysis is capable of unravelling those constructions and accessing the host of assumptions and values carried by semiotic choice.

Furthermore, our approach makes a clear distinction between the analytic stage in which focus on the objectively accessible linguistic form of the texts under analysis and the interpretative stage in which we attempt to make sense of the data.

\section{The data}

There are two sets of data which we draw upon in this study.

1. A set of 50 individual notes recording hospitalisation of patients who attempted suicide which led to their admission to psychiatric in-patient treatment facility. Participants of this project were recruited from 16 psychiatric wards in 5 psychiatric hospitals in the south west of Poland.

2. Eight recordings of psychiatric interviews along with notes in-patients' records. The data were collected in eight psychiatric wards in three psychiatric hospitals in the south of Poland. Each interview was a routine conversation between the patient and the doctor immediately after admission. They were the first encounter between the physician and the patient. Both the doctor and the patient gave informed consent to the interview being recorded, and the notes in the medical record copied and analysed discursively. The preliminary diagnosis of the interviewed patients was depressive illness (mild or moderate; F-32-33; WHO, 1998), and the doctors were residents (i.e. fully qualified doctors) training for specialisation in psychiatry.

The clinical notes give us insights into practices of recording suicide ideation, the second set sheds additional light on how the narrated experience of suicide ideation is represented in the institutional record. 
The procedure of collecting the data was as follows. After gaining the permission of the chief consultant one of us met the residents to tell them about the study and its aims. They were informed that it is a study about psychiatric interview with patients preliminarily diagnosed with depressive episode and the aim of the study is to get to know the discursive practices of the first psychiatric interview. The doctors who agreed to take part in the study gained informed consent of patients qualified for the study by the chief consultant. Then the doctors were instructed to conduct the interview 'as usual'. The permission to take a photocopy of the doctor's notes in patient's record was taken after the doctor made the entry. Thus, none of the doctors knew that we were interested in their records, before s/he recorded the interview. Photocopies were taken by the chief consultant and all personal information about the patient and the doctor was removed. Approval for the studies was obtained from the ethical committee of the Wroclaw Faculty of the University of Social Sciences and Humanities in Poland.

For analysis, first, both sets of data were thematically coded with the use of qualitative data coding software (MaxQDA). We focused on fragments in which the texts referred to a suicide attempt, and, for the purposes of this paper, the act itself, together with the preparation for it. In the process, we created a 'subcorpus' of the data, which was used in the second-stage analysis. This analysis focused upon grammatical, lexical as well as narrative patterns in the data. In the paper, we present the fragments of the informants' stories as well as clinical notes which are typical of those we identified. Importantly, while the initial stage of the data-processing involved our decision to determine which data would form the smaller corpus, the second stage of the analysis was based upon the 'objective' linguistic form which was analysed with repeatable and empirically verifiable methods of text-based discourse analysis. The analysis was based on the Polish data, however, for the purpose of this publication the analysed data were translated into English. We aimed for a translation which is as close as possible in structure and 
format to the Polish original, at the same time, trying to render the 'flavour' of what was said. This sometimes results in 'bad' or 'disjointed' English.

Finally, we do realise that the corpus we collected is limited, however, our study does not aim to be representative. We are not trying to demonstrate how widely the phenomena we discuss here occurs in psychiatry. Rather, we are interested in describing a certain problem in clinical practice. Its scale remains to be taken up in future research.

\section{Suicidal ideation in medical records}

The role assigned to suicide thoughts makes them extensively described in procedures of suicide risk assessment. The clinicians are recommended to assess the nature of suicidal thoughts by exploration of their frequency, intensity and duration (e.g. Simon, 2008a; Joint Commission, 2007). However, the clinicians are also prompted to verify potential suicidal plans along with availability and lethality of means as well as other risk factors that can trigger suicidal process (e.g. Bryan \& Rudd, 2006).

The analysis of the collected set of individual patients' notes recording hospitalisation after attempted suicide show that the doctors are interested only in suicidal ideation. There are no signs of assessment of other factors that might indicate suicide risk. What is more, the doctors noted only existence or non-existence of suicidal ideation. Suicidal ideation is recorded practically exclusively as objects outside any narrative or social context. We shall present two main strategies of reporting suicidal thoughts in the collected data.

\section{Objective entities}

The way in which doctors record suicidal information is minimal. They are recorded as objects 
existing outside any person or experience. They are objective entities. This is emphasised even more in the following five extracts in which reference to suicidal thoughts is made outside any syntactic structure:

(1) Suicidal thoughts

(2) Auto-aggressive thoughts and tendencies

(3) Ideas of resignation; suicidal tendencies!

(4) Irritable mood, without $\mathrm{ST}^{1}$

(5) suicidal thoughts present

The five extracts, which constitute references to suicide ideation in their entirety, do not contain sentences. In such a way, we would argue that the objectivity of the notes is stressed even more. Linguistically, their existence is only implied and not stated and so, in the process, it cannot be negated.

In other notes, however, suicidal ideation is stated more explicitly, as in the following extracts:

(6) resignation and suicidal thoughts appeared

(7) She has suicidal thoughts.

(8) She had suicidal thoughts.

In contrast to the earlier extract, these records introduce suicidal ideation in a sentence. That is to say, the doctor makes an explicit statement as to the thoughts' existence or appearance. The suicidal thoughts themselves, however, remain the objective objects just like in the previous group of extracts. Crucially, however, the records are made with the speaker's certainty represented as at the highest level. This is accomplished by phrasing the sentences in the third 
person singular or plural, with no qualifications, which is taken to render the speaker and his/her most certain (Hodge \& Kress, 1988). The writing doctor does not suggest that there might be any doubt as to the existence.

The main point we would like to make here is, however, that by merely stating the existence of the suicidal ideation, the doctors record it outside any personal or lived experiences. In other words, it seems that it is only the existence of suicidal ideation which is at stake here. How they are experienced, what they mean, how they relate to plans etc. seems unimportant. We would even say that the records amount to not much more than the institutional tick, the doctor confirming that $\mathrm{s} /$ he went through the motions of suicide assessment.

\section{Patients' perspectives}

Now, in this section, we discuss the other way in which suicide notes were constructed. In contrast to the records we discuss above, there were also those which explicitly introduced the patient's perspective. Consider the following examples:

(9) Confirms 's' thoughts

(10) She confirmed resignation thoughts

(11) Confirms periodically occurring resignation thoughts

(12) Confirms suicidal intent.

What is particularly interesting in these examples is that the patient's perspective is used only in order to confirm the existence of suicidal ideation. Note also that the verb 'confirm' suggests that the doctor already established the state of affairs, the patient is only asked to approve the doctor's decision. It is unclear, however, to what extent the patient's perspective is used to make the 
doctor's determination sounder, or whether it is also used as an assessment of the patient's insight.

We suggest this ambivalence because there were also a number of notes in which doctors noted not so much absence of suicidal ideation, but, rather, the patient's denial:

(13) Denies suicidal thoughts or tendencies

(14) Denies suicidal thoughts and tendencies, does not declare resignation thoughts.

(15) Currently does not confirm suicidal thoughts

(16) The patient does not confirm the thoughts and suicidal tendencies. She didn't answer many questions, especially questions about suicidal thoughts

As the doctors do not offer any views on patients' denials or not confirming, there is no evidence how the notes are intended. Our main point, however, is that despite the introduction of the perspective of the patient, the main aim of what the doctor writes remains recording existence of suicidal ideation.

Moreover, example (16) suggests that the patient's perspective may, in fact, be distrusted. We read the doctor's remarks about the patient not answering many questions as refusal of cooperation which might result from dissimulation. Put differently, the fact that the patient 'doesn't confirm' does not change the determination.

And so, as patients are reduced only to confirming or denying the doctor's pronouncement, their perspective remains ancillary to the medical one. Moreover, we have found no records in which doctors see suicidal ideation in terms of how suicide thoughts are experienced, let alone what they might mean and how (and, indeed, whether) they might be translated into action. It is worth noting that recording especially the latter aspects of suicide ideation is required of doctors (e.g. Simon, 2008b). Incidentally, we have also not seen any 
records in which doctors made note of feelings, emotions, attitudes towards life, death, suicide, whole areas of patient experience which are more than likely to be significant clinically (e.g. Chehil \& Kutcher, 2012).

\section{Transformation of interviews}

Now, looking at the notes which we have analysed above, one could come to a conclusion that the clinical interview did not carry much information concerning suicide ideation, and the meagre records simply reflect this fact. Such a conclusion would be erroneous, though. Juxtaposing the interviews with the notes which were made on its basis suggests at least that:

1. Doctors ignore the experiential aspects of suicide thoughts, treating them as a homogeneous group of cognitive activities (see also Galasinski \& Ziółkowska, 2013).

2. Even if they do explore the ideation's intensity, duration or frequency, such information does not find its way into medical records.

In an earlier study (Galasinski \& Ziółkowska, 2013) we argued that patients' narratives in clinical contexts construct their suicidal thoughts as a heterogeneous group of activities. We also suggested that they are, predominantly, narrative, as the only access to 'suicidal thoughts' can be through narrative constructions of those who speak about them. Thus, regardless of what is in 'people's heads', the stories refer to a variety of mental phenomena which escape homogenisation. We also argued, moreover, that clinical interviews suggested that psychiatrists ignored the 'thinking' dimension of 'suicidal thoughts', focusing almost exclusively on their existence and constructing it in terms of planning suicide.

The data from the medical records representing a clinical interview seem to be complementary with regard to our interview data. However, what we would like to argue here in 
particular is that the transformation of the stories of suicidal ideation suggest a stark imposition of the doctor's perspective upon the experience of the patient. In other words, when read in the context of the interview upon which they are made, the notes suggest a very clear power struggle between the perspectives of the doctor and the patient. Needless to say, the latter loses. For space we limit our discussion to two cases, which are typical of the data we have.

We start our discussion with the most striking example of complete silencing of extended stories of suicidal ideation on the part of the patient. Example (17) is the beginning of the interview and quote from an extended exchange about suicidal ideation and her earlier suicide attempts. Below, for space we focus only on the ideation which is constructed as the reason for the person's reporting to the hospital for help. We quote all explicit references to suicidal ideation made by the patient in the interview. Consider:

(17) P: Actually, it was the doctor I have seen for a long time already, she persuaded me to come to the ward because I felt very unwell. For, there are very strong suicidal thoughts. I had two suicide attempts a few years ago. And as I live alone now, the doctor was slightly afraid for me.

$[\ldots]$

D: Please tell me, what does this deterioration consists of?

P: I mean, there were strong, primarily the first signal that I have stronger, there is depression and suicidal thoughts appear. This is the first signal that I have something that it's deterioration. Because if I don't have those suicidal thoughts, even if there is depression, some reluctance or something, but there are no such strong suicidal thoughts or they do not appear at all because there are days in which these thoughts do not appear, then I function somehow. I'm calm. [...] 
D: Now, please, tell me what these suicidal thoughts are all about?

P: Reluctance to live. I feel like either hanging myself or, I don't know, I think that I will pour water into the bathtub and drown myself. I can't switch the gas on because I don't have it in the flat, but when I lived in the old one such thoughts appeared sometimes. D: You look for means?

P: I look for means, yes.

There are two points which we would like to make here. The first is that, as we indicated above, the patient explicitly constructs suicidal thoughts as the reason for her coming for help. Indeed, her medical documentation records that suicidal ideation was the reason for the patient's admission to hospital. Moreover, the patient adds that her suicidal ideation was the object of worry of her regular psychiatrist, who suggested that she should get inpatient help. It is also very clear, we think, that the patient attaches quite a lot of importance to her suicidal thoughts, seeing them as the centre of her illness experience.

Second, the account of her suicidal thoughts which the patient offers suggests that they are quite different from each other; she speaks of a reluctance to live ${ }^{1}$, feeling like hanging herself, thinking of drowning in a bathtub. Consider first that 'reluctance' is not ascribed to the patient (or anyone else), it is an abstract sentiment which, at least linguistically, exists outside any mental or social context, which suggests that the patient distances herself from it (on distancing see Galasinski, 2004). Note also that 'feeling like' doing something is likely to be different from 'thinking', and while the former might possibly suggest some translation into action, the other does not. Incidentally both feeling like and thinking are personalised and the patient takes ownership of them. The patient's stories show a complex picture of suicide thoughts as they vary 
in her account between emotions and thoughts, sometimes distancing herself from them, sometimes taking full ownership of her 'thoughts'.

Now, it is quite extraordinary that this rich and complex story of the patient is not recorded at all in the notes of the interview. Witness example (18), which is a full 'narrative' record of the patient's suicidal behaviour and/or ideation:

(18) First hospitalization of PS. Treated as outpatient for approx. 15 years. Hospitalization at home for approx. 2 years. In the interview: 2 suicide attempts by medication ingestion in approx. 2000. From approx. June deterioration - sadness and feeling of not coping, helplessness and hopelessness of the situation. Tearfulness, anxiety, insomnia. Severe nausea, lack of appetite in the morning.

The remainder of the notes reports on the family and professional situation of the patient. And so, despite the fact that the patient was admitted because of her suicidal thoughts, the notes completely silence them and the only reference to the patient's suicidality is the reference to her earlier two suicide attempts.

We think this is an instance of the doctor's exercising complete power over the patient's perspective. Not only must the patient experience give way to the medical perspective, but in this case, it must give way completely, as it is silenced. The medical gaze (Foucault, 1973) ignores it, as the clinical notes do not even mention the possibility of a different take on reality. Incidentally, this note harks right back to the first group of records we quoted. As they were outside any syntactic structure and through this much less challengeable, this note, by eliding the patient experience completely, does not even offer the opportunity of a challenge. The suicidal ideation simply disappeared. 
This note is the most extreme imposition of medical power over the experience of suicidality. Below we quote another one in which such power is somewhat negotiated, still, the doctor very clearly imposes his perspective on what the patient says. Consider first an extract from the interview:

(19) D: Are there any such unpleasant thoughts, to hurt yourself?

P: No.

D: no. There was never anything like that?

P: There wasn't.

D: There weren't any suicide attempts?

P: No.

D: Never. yhm. And are there such thoughts of death, about dying?

P: No

D: No no. no. and such total pessimism doesn't exist yet?

P: Doesn't exist.

D: Doesn't exist. Doesn't exist. good.

This interview is interesting not only because the patient is not very cooperative with the doctor, preferring to respond in monosyllables, probably resisting an almost aggressive line of questioning, but also because of the kind of questions the doctor asks. Note that they focus entirely of 'being there', or existing. None of the questions asks the patient to tell the doctor about what he feels or thinks. Yet, the patient is very clear in his answers, in fact, the answers could not be clearer. The doctor, however seems unhappy with them, as she makes the following note in the patient's records (which is the only reference to suicide ideation):

(20) Denies suicidal thoughts. 
It is unclear why the doctor decides to put the verb 'deny' and the notes do not offer any indication why the verb might be used. And yet, importantly, the verb can be seen as undermining the patient. This is because the verb 'deny' suggests that the doctor might have suspected suicide ideation, explored it and is not convinced by the patient's answer. A denying person contradicts that suspicion or perhaps reality (note the use of 'denier' in the phrase 'Holocaust denier').

One can, of course, wonder, what status is a psychiatrist's suspicion. The reference to denying might also be used as a means of not only suggesting that the doctor had considered and explored the issue with the patient, but also precisely as a way of raising suspicion about the patient's veracity. In the process, by undermining the patient, the doctor might also be simply covering their back in the case her or his suspicions turn out to be correct.

\section{Conclusions}

In this article, we explored ways in which suicidal ideation is represented in medical records. Put differently, we were interested in constructions of suicidal experiences in the institutional discourse of psychiatry. Our argument is two-fold. On the one hand, we argue that as psychiatrists focus predominantly on occurrence, or existence of suicidal ideation, its experiential aspects are ignored. They do it by constructing suicidal ideation and objective phenomena existing outside any experiential context. In fact, the patient's perspective in the notes was used solely to confirm the doctor's determination as to whether suicidal ideation occurs or not.

Such practices were also used in the transformation of patient experience in medical records. The imposition of the medical perspective not only dominates, but also puts a value 
judgement of on the experiential one. However, we cannot speak to the prevalence of such practices in psychiatric discourses, still no evidence of attempts to see suicidal ideation as part of the patient's experience is consistent with the dominance of the medical model in psychiatry. We accept that this must be explored further.

We would like to conclude this paper by taking up a number of points which in our view are raised by the discursive practices we have just described. The most striking one is the implicit homogenisation of suicidal thoughts and looking at them only through the lens of a symptom checklist. Suicidal thoughts, further, are not seen as a meaningful part of the experience of distress or difficulty, but are relegated to a tick box exercise. Moreover, in such a way suicide ideation remains acontextual phenomenon outside any social and psychological contexts.

We do acknowledge, however, that the patients were diagnosed with a depressive disorder. Suicide ideation is one of the symptoms and it is likely that doctors were assessing the existence of such thoughts, possibly also to reaffirm the diagnosis of depression. If such an interpretation of what we found in the notes is tenable, then it shows the dominance of the biomedical model focusing on the symptoms, which in turn serves to perpetuate the dominant model. In the process, the existence of suicide ideation only leads to the diagnosis which is what the clinician must focus on. ${ }^{2}$

Furthermore, as they ignore the individual context of suicidal thoughts, doctors seem not to reflect on the meaning of suicidal thoughts, or, really, stories about them, in such a context. As they confirm (or not) what they think, they also do not record any reasoning behind their determination. The minimal linguistic form, cushioned in no additional narrative, offers no insight whatsoever into why the clinician decides that suicidal thoughts 'occur' or not, always as if they existed in abstraction of anyone actually thinking them.

It is important to stress that such practices do not follow guidelines in the literature both 
on keeping medical records related to suicide risk and procedures of assessing such risks (e.g. Simon, 2008a), and as such it has no diagnostic or therapeutic advantages. Clinical interviews which focus not on determining the occurrence of suicidal thoughts, but on their experience, seem to be considerably more useful. This is because, on the one hand, suicidal thoughts are not a clear predictor of suicidal behaviour (Nock, et al., 2008; Glenn \& Nock, 2014), but also because some patients simply hide them (Busch, Fawcett, \& Jacobs, 2003; Barber, Marzuk, Leon, \& Portera, 2001). Moreover, in a recent study, Ziółkowska (2016) explores stories of suicidal ideation and shows that in such narratives suicidal thoughts are constructed as 'beyond control' of the people who have them, suggesting a very complex experience which, if anything, should be explored clinically (and also in further research). Still, the question, then, of what exactly medical records tell clinicians is as pertinent as it is probably unanswerable.

Moreover, as uncertainty is an inevitable part of suicide assessment (Simon, 2006), it seems that the notes which we have analysed attempt to do away with it completely, as doctors' pronouncements are final and non-negotiable. The notes do not seem to reflect any process of negotiation, clinical judgement, or indeed, the process of decision making with regard to the patient's experience. As they focus on occurrence of suicidal ideation they construct an all-ornothing reality which is quite unlikely to exist in reality. One could also speculate whether this is precisely the reason why medical records, together with the adoption of the non-negotiable medical gaze seem to push patients' lived experience out of the scope of interest of doctors and, perhaps, psychiatry in generally. The messy experience of the psychiatric patient might not be a good fit for the world of certainty offered by his or her doctor. 


\section{References}

Barber, M. E., Marzuk, P. M., Leon, A. C., \& Portera, L. (2001). Gate questions in psychiatric interviewing: The case of suicide assessment. Journal of Psychiatric Research, 35(1), 67-69.

Barker, C. \& Galasiński, D. (2001). Cultural Studies and Discourse Analysis: a dialogue on language and identity. London \& Thousand Oaks: Sage.

Beck, A. T., Kovacs, M., \& Weissman, A. (1979). Assessment of suicidal intention: the Scale for Suicide Ideation. Journal of Consulting and Clinical Psychology, 47(2), 343-352.

Beck, A., Schuyler, D. \& Herman, J. (1974). Development of suicidal intent scales. In A. Beck, H. Resnik \& D. J. Lettieri (eds.), The Prediction of Suicide (45 -56). Bowie, MD: Charles Press.

Bryan, C. J., \& Rudd, M. D. (2006). Advances in the assessment of suicide risk. Journal of Clinical Psychology, 62(2), 185-200.

Busch, K. A., Fawcett, J., \& Jacobs, D. G. (2003). Clinical correlates of inpatient suicide. Journal of Clinical Psychiatry, 64(1), 14-19.

Buus, N. (2009). How writing records reduces clinical knowledge: A field study of psychiatric hospital wards. Archives of Psychiatric Nursing, 23(2), 95-103.

Carrigan, C. G., \& Lynch, D. J. (2003). Managing suicide attempts: guidelines for the primary care physician. Primary Care Companion to the Journal of Clinical Psychiatry, 5(4), 169-174.

Chehil, S., \& Kutcher, S. P. (2012). Suicide risk management: A manual for health professionals. Chichester: John Wiley \& Sons.

Conrad, A. K., Jacoby, A. M., Jobes, D. A., Lineberry, T. W., Shea, C. E., Arnold Ewing, T. D., ... \& Grenell, J. A. (2009). A psychometric investigation of the Suicide Status Form II 
with a psychiatric inpatient sample. Suicide and Life-Threatening Behavior, 39(3), 307320.

Davidson, L. (2003). Living outside Mental Illness. New York: New York University Press.

Deisenhammer, E. A., Strauss, R., Kemmler, G., Hinterhuber, H., \& Weiss, E. M. (2009). The duration of the suicidal process: how much time is left for intervention between consideration and accomplishment of a suicide attempt? The Journal of Clinical Psychiatry, 70(1), 19-24.

Fairclough, N. (1992). Discourse and social change. Cambridge: Polity Press.

Fartacek, C., Schiepek, G., Kunrath, S., Fartacek, R., \& Plöderl, M. (2016). Real-Time Monitoring of Non-linear Suicidal Dynamics: Methodology and a Demonstrative Case Report. Frontiers in psychology, 7. Retrieved from http://journal.frontiersin.org/article/10.3389/fpsyg.2016.00130/full

Foucault, M. (1973). The Birth of the Clinic: An Archaeology of Medical Perception. New York: Vin-tage Books.

Galardy, Ch. A. \& Lineberry, T. W. (2013). Hospitalization as Suicide Prevention. In D. Lester \& J. R. Rogers (Eds.), Suicide. A Global Issue. Vol. 2. (pp. 91-108). Santa Barbara: Preager.

Galasinski, D. (2004). Men and the Language of Emotions. Basingstoke: Palgrave Macmillan. Galasinski, D., \& Ziólkowska, J. (2013). Experience of suicidal thoughts: A discourse analytic study. Communication \& Medicine, 10(2), 117-127.

Glenn, C. R., \& Nock, M. K. (2014). Improving the short-term prediction of suicidal behavior. American Journal of Preventive Medicine, 47(3), 176-180.

Griffith, R. (2007). The importance of earnest record-keeping. Nurse Prescribing, 5(8), 363-366. 
Heartfield, M. (1996). Nursing documentation and nursing practice: a discourse analysis. Journal of Advanced Nursing, 24(1), 98-103.

Higgs, J., \& Jones, M. (2000). Clinical reasoning in the health professions. Oxford: ButterworthHeineman.

Hodge, B. \& Kress, G. (1993). Language as Ideology. London: Routledge.

Hodge, R., \& Kress, G. (1988). Social Semiotics, Oxford: Polity Press.

Huber, C. G., Schneeberger, A. R., Kowalinski, E., Fröhlich, D., von Felten, S., Walter, M., ... \& Lang, U. E. (2016). Suicide risk and absconding in psychiatric hospitals with and without open door policies: a 15 year, observational study. The Lancet Psychiatry, 3(9), 842-849.

Jobes, D. A. (2006). Managing suicidal risk: a collaborative approach. New York: Guilford Press.

Jobes, D. A., Jacoby, A. M., Cimbolic, P., \& Hustead, L. A. T. (1997). Assessment and treatment of suicidal clients in a university counseling center. Journal of Counseling Psychology, 44(4), 368-377.

Joint Commission (JCAHO) (2007). Suicide Prevention: Toolkit for Implementing National Patient Safety Goal 15A. Oak Brook: Joint Commission Resources.

Kapur, N., House, A., Dodgson, K., May, Ch., Creed, F. (2002). Effect of general hospital management on repeat episodes of deliberate self poisoning: cohort study. BMJ, 325, 866-867.

Laukkala, T., Partonen, T., Marttunen, M., \& Henriksson, M. (2014). Suicides among military conscripts between 1991-2007 in Finland-A descriptive replication study. Nordic Journal of Psychiatry, 68(4), 270-274. 
Mallon, S., Galway, K., Hughes, L., Rondón-Sulbarán, J., \& Leavey, G. (2016). An exploration of integrated data on the social dynamics of suicide among women. Sociology of Health \& Illness, 38(4), 662-675.

Menz, F. (1989). Manipulation strategies in newspapers. In R. Wodak (ed.), Language, Power and Ideology. Amsterdam: John Benjamins.

Mohr, W. K., \& Noone, M. J. (1997). Deconstructing progress notes in psychiatric settings. Archives of psychiatric nursing, 11(6), 325-331.

Neeleman, J., de Graaf, R., \& Vollebergh, W. (2004). The suicidal process; prospective comparison between early and later stages. Journal of Affective Disorders, 82(1), 43-52.

Nock, M. K., Borges, G., Bromet, E. J., Alonso, J., Angermeyer, M., Beautrais, A., ... Williams, D. (2008a). Cross-national prevalence and risk factors for suicidal ideation, plans and attempts. The British Journal of Psychiatry, 192(2), 98-105.

Perron, A., \& Holmes, D. (2011). Constructing mentally ill inmates: Nurses' discursive practices in corrections. Nursing inquiry, 18(3), 191-204.

Poulin, C., Shiner, B., Thompson, P., Vepstas, L., Young-Xu, Y., et al. (2014). Predicting the Risk of Suicide by Analyzing the Text of Clinical Notes. PLoS ONE 9(1), e85733. doi:10.1371/journal.pone.0085733

Runeson, B. S., Beskow, J., \& Waern, M. (1996). The suicidal process in suicides among young people. Acta Psychiatrica Scandinavica, 93(1), 35-42.

Shea, S.C. (2009a). Suicide assessment: part 1: uncovering suicidal intent, a sophisticated art. Psychiatric Times. Retrieved from http://www.psychiatrictimes.com/akineticmutism/suicide-assessment-part-1-uncovering-suicidal-intent—-sophisticated-art

Shea, S.C. (2009b). Suicide Assessment Part 2: Uncovering Suicidal Intent Using the CASE Approach. Psychiatric Times. Retrieved from 
http://www.psychiatrictimes.com/suicide/suicide-assessment-part-2-uncoveringsuicidal-intent-using-case-approach

Simon, R. I. (2006). Patient safety versus freedom of movement: Coping with uncertainty. In R. I. Simon \& R. E. Hales (Eds.), The American Psychiatric Publishing textbook of suicide assessment and management (pp. 423-439). Washington, DC: American Psychiatric Publishing.

Simon, R. I. (2008b). Suicide. In R. E. Hales, S. C. Yuodofsky, G. O. Gabbard (Eds.). The American psychiatric publishing textbook of psychiatry (pp. 1637-1654). Washington: American Psychiatric Publishing.

Simon, R. I. (2008a). Assessing and managing suicide risk: Guidelines for clinically based risk management. Washington: American Psychiatric Publishing.

Simon, R. I., \& Hales, R. E. (Eds.). (2012). The American Psychiatric Publishing textbook of suicide assessment and management. Washington: American Psychiatric Publishing.

Simpson, S., \& Stacy, M. (2004). Avoiding the malpractice snare: Documenting suicide risk assessment. Journal of Psychiatric Practice, 10(3), 185-189.

Tasman, A., \& Mohr, W. K. (2011). Fundamentals of Psychiatry. Oxford: John Wiley \& Sons. The Joint Commission (2016). Detecting and treating suicide ideation in all settings. Retrieved from https://www.jointcommission.org/assets/1/18/SEA_56_Suicide.pdf

The Commissioner for Patients' Rights (2016). The report on respect of patients' rights in Poland. Retrieved from https://www.bpp.gov.pl/gfx/bpp/userfiles/_public/bip/sprawozdania_roczne/sprawozdani e_rpp_2015.pdf

Van Dijk, T. A. (1993). Principles of critical discourse analysis. Discourse \& Society, 4(2), 249283. 
Waldinger, R. J. (1997). Psychiatry for Medical Students. Washington: American Psychiatric Press.

WHO, World Health Organization (1998) Klasyfikacja zaburzeń psychicznych i zaburzeń zachowania w ICD-10 (polish translation of WHO, 1993). Kraków-Warszawa: VesaliusIPiN.

Ziółkowska, J. (2016). Samobójstwo. Analiza narracji osób po próbach samobójczych. Warszawa: PWN. 


\section{Notes}

1 The original Polish note had 'MS', an abbreviation standing for 'myśli samobójcze', that is 'suicidal thoughts'. In the English translation, we rendered the abbreviation as 'ST'.

${ }^{2}$ We are grateful to Jason Bantjes for drawing our attention to the issue. 